\title{
Survey of platelet glycoprotein specific antibodies and HLA class 1 antibodies in a cross section of Nigerian multiparous women
}

\author{
Zaccheaus Awortu Jeremiah, Justina Egwuma Oburu
}

\begin{abstract}
Aims: The frequencies of alloantibodies to platelet glycoproteins and HLA class 1 have not been reported in this part of the world. To determine the prevalence of these antibodies in Nigeria. Methods: The sera of 100 multiparous women were tested for antibodies to HPA and HLA class 1 antigens using GTI PakPlus solid phase ELISA Kit in a cross sectional study. Results: The prevalence of platelet glycoproteins specific antibodies was obtained as follows: GP IIb/IIIa (10\%), GP Ia/IIa (48\%), GP IV (8\%) and GP Ib/IX (12\%). Further analysis revealed the prevalence of each platelet antibody subgroup as follows: anti-HPA-1a,-3a,4a (o\%), anti-HP-1b,-3a,-4a (10\%), anti-HPA-5a (18\%), anti-HPA-5b (30\%). HLA class 1 antibody was prevalent in $22 \%$ cases. The production of these antibodies was parity dependent. Conclusions: There is a high prevalence of antiHPA-5b and anti-HLA class 1 in our female population which can pose potential threat to our blood donor pool.
\end{abstract}

Zaccheaus Awortu Jeremiah ${ }^{1}$, Justina Egwuma Oburu ${ }^{2}$ Affiliations: ${ }^{1}$ Haematology and Blood Transfusion Unit, Department of Medical Laboratory Sciences, College of Health Sciences, Niger Delta University, Wilberforce Island, Bayelsa State, Nigeria; 2Department of Haematology and Blood Transfusion, University of Port Harcourt Teaching Hospital, Port Harcourt, Nigeria.

Corresponding Author: Zaccheaus Awortu Jeremiah Ph.D, P.O.Box 1437, Diobu, Port Harcourt 500001, Rivers State, Nigeria; Ph: +234 (803) 404 5636;

Email: zacjerry@yahoo.com

Received: 10 February 2011

Accepted: 11 April 2011

Published: 15 October 2011
Keywords: Platelet glycoproteins, Platelet antibodies, HLA class 1 antibodies, Multiparous women, Nigeria

$* * * * * * * * *$

Jeremiah ZA, Oburu JE. Survey of platelet glycoprotein specific antibodies and HLA class 1 antibodies in a cross section of nigerian multiparous women. International Journal of Blood Transfusion and Immunohematology 2011;1:7-11.

Article ID: 100002IJBTIZAJ2011.

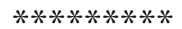

doi:10.5348/ijbti-2011-2-OA-2

\section{INTRODUCTION}

Formation of antibodies to human platelet specific antigens (HPA) and human leucocyte antigens (HLA) class 1 are among the non-infectious risk of blood transfusion that has been identified [1]. These plateletspecific and HLA class 1 antigens are carried on the platelet membrane glycoproteins which occur as heterodimeric compounds i.e. each consisting of two different glycoprotein molecules [2]. Platelet glycoproteins are therefore often paired (e.g. Ia/IIa, IIb/IIIa or Ib/IX referring to the alpha and beta chains in each complex) [2]. The GP Ia/IIa and IIb/IIIa complexes are members of the broadly distributed family of adhesion molecules called integrins, which are essential for platelet adhesion and aggregation because they serve as receptors for ligands such as fibrinogen, von willebrand factor, collagen and fibronectin. GP $\mathrm{Ib} / \mathrm{IX}$ is a leucine rich membrane glycoprotein and plays a major role in primary haemostasis [2-4]. GP IV (CD 36) is a membrane glycoprotein that is highly but variably expressed on platelets [5]. 
HLA and platelet specific antibodies do not occur naturally but are acquired through exposure to alloantigens through pregnancy and blood transfusion. These antibodies have been incriminated in several clinical conditions ranging from transfusion related acute lung injury (TRALI) caused by HLA class 1 antibodies to neonatal alloimmune thrombocytopenia (NAIT), platelet refractoriness (PR) and post transfusion purpura (PTP) caused by platelet specific antibodies [6-11].

The female population anywhere in the world forms part of the blood donor pool and majority of them are multiparous women. Although these women could be good long term donors, multiple pregnancies expose them to the risk of developing higher than usual titres of HPA and HLA antibodies to the foetal antigens of paternal origin $[12,13]$.

It is hypothesized that in a typical African setting where the cultural beliefs encourage multiple pregnancies, the proportion of these antibodies could be high among multiparous women thus rendering them "dangerous blood donors".

There is no data in our country reporting the incidence or prevalence of these antibodies. This study was therefore aimed at determining the prevalence of HPA and HLA class 1 antibody among multiparous females and assesses the influence of age and parity on the production of these antibodies.

\section{MATERIALS AND METHODS}

Subjects: The study population consisted of 100 apparently healthy multiparous women recruited from the staff of the University of Port Harcourt Teaching Hospital (UPTH), Port Harcourt. They all had given birth to all least two children and had no children in the one year prior to the study. The age range was from 26-59 years (mean $40.6 \pm 8.4$ years). Their parity ranged from $2-11$ with a mean of $4.0 \pm 1.9$. Their parity status was grouped into two, those having less than or equal to four children constituted the highest percentage (72.0\%) while those having more than or equal to five children constituted 28.0\%. These subjects were selected randomly from February to June, 2009.

Serological Studies: All specimens were tested in duplicate and examined to detect HLA class 1 and platelet specific glycoprotein by a US-FDA licensed commercial solid-phase enzyme-linked immunosorbent assay kit, PakPlus (GTI; Waukesha, WI, USA). Testing performed was for polymorphic epitopes of the specific platelet antigens; including GP IIb/IIIa, GP Ia/IIa (HPA-5b/5b), GP Ia/IIa (HPA-5a/5a), GP IV, GP Ib/IX and isolated HLA class 1 antigen, immobilized in specific wells of the microplate.

Subject's serum was added to micro wells coated with platelet and HLA glycoprotein allowing antibody, if present to bind. Unbound antibodies were then washed away. An alkaline phosphate labelled anti-human globulin reagent (anti-IgG/A/M) was added to the wells and incubated. The unbound anti-IgG/A/M was washed away and the substrate P-Nitro-Phenyl phosphate (PNPP) was added. After 30 minutes incubation period, the reaction was stopped by a sodium hydroxide solution. The optical density of the colour that developed was measured in an ELISA reader at wavelength 405 or $410 \mathrm{~nm}$. The results were calculated and interpreted based on the instructions provided by the manufacturer.

Statistics: The frequency and difference of antibody presence in age and parity were evaluated by the Pearson Chi-square test using statistical package for the social sciences (SPSS) (Version 17, Chicago, IL, USA). A $\mathrm{p}$ value of less than 0.05 was considered statistically significant.

\section{RESULTS}

Table 1 shows the age and parity of the one hundred multiparous women. Women of the age group 35-44 years constituted the majority (40\%), followed by those in the 25-34 years age bracket (28\%), then $45-54$ years (26\%) and 6\% for 55 years and above. The proportion of the women who had less than or equal to four children were $72 \%$ while those with parity five and above constituted $28 \%$ of the study population.

Table 1: Age and parity status of the 100 multiparous women.

\begin{tabular}{cc}
\hline Characteristics & Percentage \\
\hline Age groups & \\
$25-34$ & $28.0 \%$ \\
$35-44$ & $40.0 \%$ \\
$45-54$ & $26.0 \%$ \\
55 and above & $6.0 \%$ \\
Parity & \\
$\leq 4$ & $72.0 \%$ \\
$\geq 5$ & $28.0 \%$ \\
\hline
\end{tabular}

The prevalence of HLA class 1 antibody was $22 \%$ while the remaining $78 \%$ accounted for platelet glycoprotein specific antibody. The distribution of the platelet glycoprotein antibodies were as follows: antiGP-IIb/IIIa (10\%), anti-GP-Ia/IIa (48\%), anti-GP IV (8\%) and anti-GP-Ib/IX (12\%). These results are shown in table 2.

To further analyze the prevalence of each platelet antibody sub-group, the proportion is shown in table 3 . Anti-HPA-Ia, -3a, -4a (o\%), anti-HPA-1b, -3b, -4a (10\%), anti-HPA -5a (18\%), anti-HPA-5b (30\%) anti-GP $\mathrm{Ib} / \mathrm{IX}(12 \%)$ and anti-GP IV (8\%).

The influence of age and parity on the prevalence of the antibodies (HPA and HLA antibodies) is shown in table 4. Apart from anti-HPA-1a, $-3 \mathrm{a}-4 \mathrm{a}$ which did not occur in this study population, Fishers exact test analysis revealed that there is a strong association between parity, platelet and HLA class 1 antibody at various levels of significance. Age was selectively found to associate significantly with anti-HPA-5b (Fisher's exact 5.679, $\mathrm{p}<0.05)$ and HLA class 1 antibodies. (Fishers exact 14.188, $\mathrm{p}<0.001$ ) 
Table 2: Production of HLA class 1 and platelet antibodies among the 100 multiparous women.

\begin{tabular}{lc}
\hline Antibody & Percentage positive \\
\hline HLA class 1 antibody only & $22 \%$ \\
Platelet specific antibodies only & $78 \%$ \\
GP IIb /IIIa & $10 \%$ \\
GP Ia/IIa & $48 \%$ \\
GP IV & $8.0 \%$ \\
GP Ib/IX & $12.0 \%$ \\
HLA class 1 and platelet specific & \\
antibodies & \\
HLA + GP Ia/IIa & $44 \%$ \\
HLA + GP Ia/IIa + GP IV & $2.0 \%$ \\
HLA + GP Ia/IIa + GP Ib/IX & $8.0 \%$ \\
HLA + GP IIb/IIIa & $4.0 \%$ \\
HLA + GP IIb/IIIa + GP Ia/IIa + & $2.0 \%$ \\
GP Ib/IX + GP IV & \\
\hline
\end{tabular}

Table 3: Proportion of different antibodies among multiparous women producing platelet specific antibodies.

\begin{tabular}{lc}
\hline Antibodies of platelets & Percentage positive \\
\hline All GP IIb/IIIa & $10.0 \%$ \\
Anti- HPA-1a,-3a -4a & $0 \%$ \\
Anti-HPA-Ib,-3b,-4a & $10.0 \%$ \\
All GP Ia/IIa & $48.0 \%$ \\
Anti-HPA 5a & $18.0 \%$ \\
Anti-HPA-5b & $30.0 \%$ \\
All GP Ib/IX & $12.0 \%$ \\
All GP IV & $8.0 \%$ \\
\hline
\end{tabular}

\section{DISCUSSION}

This study describes the prevalence of antibodies to human platelet antigens and human leucocytes antigens (HLA) class 1 in a cross section of Nigerian multiparous women. The main findings of this study are 1) the high prevalence of anti-HPA-5b and HLA class 1 antibodies; 2) the zero prevalence of anti-HPA-1a,-3a,-4a; 3) the significant influence of the number of previous pregnancies on the occurrence of both HPA and HLA class 1 antibodies.

The findings of the high prevalence of anti-HPA-5a and anti-HPA-5b are consistent with observation of maternal HPA alloimmunization in other populations like Tunisia, Austria and United States [14-18]. In these countries, ant-HPA-5b was also shown to be of highest prevalence whereas the detection of anti-HPA-1a is a rare event, in Caucasians occurring in 1-2 cases among 500-1000 pregnant women $[19,20]$. Thus the zero prevalence of anti-HPA-1a, $-3 \mathrm{a},-4 \mathrm{a}$ in this study could be due to the relatively small size of the study population.

Second to anti HPA-5b is the prevalence of antiHLA-class 1 antibodies (22.0\%). This high prevalence is comparable with $20.7 \%$ prevalence rate obtained from maternal sera of pregnant women in Hyderabed, India [21] and Korea [24].

The most serious consequences of the presence of platelet antibodies and HLA class 1 antibodies are the possibilities of the occurrence of clinical disorders known as neonatal alloimmune thrombocytopenia (NAIT), platelet refractoriness (PR), post transfusion purpura (PTP) caused by anti-HPA antibodies and

Table 4: Influence of parity and age on the prevalence of platelet and HLA class 1 antibodies.

\begin{tabular}{|c|c|c|c|c|c|c|c|}
\hline Antibodies & HPA- Ia/3a/4a & $\mathrm{HPA}-1 \mathrm{~b} / 3 \mathrm{~b} / 4 \mathrm{a}$ & HPA-5b & HPA-5a & GP Ib/IX & GP IV & HLA \\
\hline Parity Status & Pos. & Pos. & Pos. & Pos. & Pos. & Pos. & Pos. \\
\hline$\leq 4$ & O & 4.0 & 14.0 & 8.0 & 8.0 & 2.0 & 10.0 \\
\hline$\geq 5$ & $\mathrm{O}$ & 6.0 & 19.0 & 10 & 4.0 & 4.0 & 12.0 \\
\hline $\begin{array}{l}\text { Fisher's } \\
\text { exact }\end{array}$ & $\mathrm{O}$ & $7.902^{*}$ & $11.683^{* *}$ & $13.57^{* *}$ & $6.54^{*}$ & $8.917^{*}$ & $10.891^{* *}$ \\
\hline $\begin{array}{l}\text { Age groups } \\
\text { (Yrs) }\end{array}$ & $\mathrm{O}$ & & & & & & \\
\hline $25-34$ & $\mathrm{O}$ & 2.0 & 8.0 & 2.0 & 4.0 & $\mathrm{O}$ & 6.0 \\
\hline $35-54$ & $\mathrm{O}$ & 4.0 & 6.0 & 8.0 & 2.0 & 2.0 & $\mathrm{O}$ \\
\hline $45-54$ & $\mathrm{O}$ & 4.0 & 14.0 & 8.0 & 4.0 & 4.0 & 1.0 \\
\hline 55 and above & $\mathrm{O}$ & $\mathrm{O}$ & 2.0 & $\mathrm{O}$ & 2.0 & $\mathrm{O}$ & 2.0 \\
\hline Fisher's exact & - & $0.971^{(n s)}$ & $5.679^{*}$ & $2.729^{(n s)}$ & $3.083^{(\mathrm{ns})}$ & 2.788 (ns) & $14.188^{* * *}$ \\
\hline
\end{tabular}

$*$ Significant a $\mathrm{p}<0.05 ; \quad * *=$ Significant at $\mathrm{p}<0.01 ; \quad * * *=$ Significant at $\mathrm{p}<0.001 ; \mathrm{ns}=$ Not significant; Pos. $=$ Positive 
transfusion related acute lung injury (TRALI) caused by anti-HLA class 1 antibodies. Anti HLA class 1 antibodies have also been implicated in some case of NAIT $[8,22-$ 26].

Another aspect of the relevance of this study is that women are part of the blood donor pool and in our African setting where the cultural beliefs encourage frequent pregnancies, many of our female blood donors may actually be "dangerous blood donors" due to the presence of circulating HPA and HLA antibodies as observed in this study. More so, the presence of these antibodies showed a very significant association with parity. It follows therefore that the women with more frequent pregnancies carries higher potential to make both platelet and HLA antibodies. Since all the participants have stopped child bearing for the past one year prior to inclusion in this study, it means that the antibodies once developed can persist in their circulation for a long time.

In conclusion, this study has identified a high prevalence of HPA and HLA class 1 in the Nigerian female population. There is need to screen our female blood donors who have previous histories of frequent pregnancies in order to ensure safety in our blood supply to transfusion recipients.

$$
* * * * * * * * *
$$

\section{Author Contributions}

Zaccheaus Awortu Jeremiah - Substantially contributed to conception and design, acquisition of data , drafting the article, revising it critically for important intellectual content and final approval of the version to be published Justina Egwuma Oburu - Contributed tto conception and design, analysis and interpretation of data and final approval of the version to be published

\section{Guarantor}

The corresponding author is the guarantor of submission.

\section{Conflict of Interest}

Authors declare no conflict of interest.

\section{Copyright}

(C) Zaccheaus Awortu Jeremiah et al. 2011; This article is distributed under the terms of Creative Commons attribution 3.0 License which permits unrestricted use, distribution and reproduction in any means provided the original authors and original publisher are properly credited. (Please see www.ijbti.com/copyrightpolicy.php for more information.)

\section{REFERENCES}

1. Brecher ME. (ed). Technical Manual (14th ed) Bethesda USA: American Association of Blood Banks (AABB) 2002:pp341-59.

2. Lopez JH, Chung DW, Fujikawa K. The alpha and beta chains of human platelet glycoprotein $\mathrm{Ib}$ are both transmembrane proteins containing a leucine rich amino acid sequence. Proc Natl Acad Sci USA 2001;85:2135-9.

3. Ruggeri ZM. von Willebrand factor, platelets and endothelial cell interactions. Thrombos Haemost 2003;1:1335-7.

4. Nozaki S, Tanaka T. Yamashita S. CD 36 mediate long chain fatty acid transport in human myocardium: complete myocardium accumulation defect of radio labelled long chain fatty acid analog in subjects with CD 36 deficiency. Mol Cell Biochem 1999;192:129-37.

5. Hirano K, Kuwasako T, Nakagawa - Toyama Y. Pathophysiology of human genetic CD 36 deficiency. Trends Cardiovasc Med 2003;13:136-41.

6. Reil A, Keller-Stanislawski B, Gunay S, Bux J. Specificities of leucocyte alloantibodies in transfusion related acute lung injury and results of leucocyte antibody screening of blood donors. Vox Sang 2008;95:313-7.

7. Sachs UJ, Link E. Hofmann C, Wasel W, Bein G. Screening of multiparous women to avoid transfusion-related acute lung injury: a single centre experience. Transfus Med 2008;18:348-54.

8. Grainger JD, Morrel G, Yates J, Deleacy D. Neonatal alloimmune thrombocytopenia with significant HLA antibodies. Arch Dis Child Fetal Neonatal Ed 2002;86:F200-1.

9. Campbell-Lee SA, DeSantis-Parsons D, Sue Shirey R, Kickler TS. Neonatal alloimmune thrombocytopenia due to anti-HPA-5b(Bra). Immunohematology 2003;19:127-31.

10. Moncharmont $\mathrm{P}$, Dubois V, Obegi C, et al. HLA antibodies and neonatal alloimmune thrombocytopenia. Acta Haematologica 2004;111:215-20.

11. Ohto H, Miura S, Ariga H, et al. The natural history of maternal immunization against foetal platelet alloantigens. Transfus Med 2004;14:399-8.

12. Boehlen F, Bulla O, Michel M, Reber G, de Moerloose P. HPA genotyping and antiplatelet antibodies in female blood donors. The Hematol J 2003;4:441-4.

13. Schnaidt M, Wernet D. Platelet specific antibodies in female blood donors after pregnancy. Transfus Med 2000;10:77-80.

14. Christie DJ. Pulkrabek S, Putnam JL, Slatkoff ML, Pischel KD. Post transfusion purpura due to an alloantibody reactive with glycoprotein Ia/IIa (antiHPA-5b). Blood 1999;77:2785-9.

15. Ranzer S, Auerbach L, Cechova E. Maternal alloimmunization against platelet antigens: a prospective study. Br J Haematol 1995;90:655-60.

16. Kjeldsen-Kragh J, Killie MK, Tomter GA. Screening and intervention programme aimed at reducing mortality and morbidity associated with neonatal thrombocytopenia. Blood 2007;110:833-5.

17. Bussel JB, Zabusky Mr, Berkowitz RL, MeFarland JG. Fetal alloimmune thrombocytopenia. N Engl J Med 1997;337:22.

18. Schnaidt M, Wemet D. Platelet-specific antibodies in female blood donors after pregnancy. Transfus Med 2000;10:77-80.

19. kjeldsen-kragh J, kim M, killie MK, Husebekk A, Freedman J, Semple JW. In HPA 1a-immunized women the decrease in anti-HPA 1a antibody level during pregnancy is not associated with antiidiotypic antibodies. Haematologica 2009 Mar;94(3):441-3 
20. Killie MR, Husebelek A, Kjeldsen - Kragh J, Skogen B. A. prospective study of maternal anti-HPA-1a antibody level as a potential predictor of alloimmune thrombocytopenia in the newborn. Haematologia 2008;93:870-7.

21. Naik $P$, Indira $S$, Pitchappan RM, Malati $T$. Screening of HLA antibodies in maternal sera from Hyderabad. Ind J Clin Biochem 1991;6:119-23.

22. Legler TJ, Fischer I, Dittman J, et al. Frequency and causes of refractoriness in multiply transfused. Ann Hematol 1997;74:185-9.

23. Brubaker DB, Romine M. Relationship of HLA and platelet reactive antibodies in alloimunized patient's refractory to platelet therapy. Am J Hematol 1987;26:341-52.

24. Song EY, Kini SM, Kim BC, Han KS, Park MH. Positive rate of HLA class 1 antibodies in multiparous Korean women. Korean J Clin Pathol 2000;20:210-14.

25. Chang BC, Liao YS, Chang LF, Wang HL. Survey of platelet glycoproteins specific antibodies and HLA class 1 antibodies in haemodialysis patients. J Biomed Lab Sc 2009;20:64-8.

26. Davoren A, Smith OP, et al. Case report: four donors with granulocyte-specific or HLA class 1 antibodies implicated in a case of transfusion - related acute Lung injury (TRALI). Immunohematology 2001;17:117-21. 